\title{
Lack of Glycoprotein 130/Signal Transducer and Activator of Transcription 3-Mediated Signaling in Hepatocytes Enhances Chronic Liver Injury and Fibrosis Progression in a Model of Sclerosing Cholangitis
}

\author{
Werner Plum, ${ }^{\star}$ Darjus F. Tschaharganeh, ${ }^{\dagger}$ \\ Daniela C. Kroy, ${ }^{*}$ Eva Corsten, ${ }^{*}$ \\ Stephanie Erschfeld, ${ }^{*}$ Uta Dierssen, ${ }^{*}$ \\ Hermann Wasmuth, ${ }^{*}$ Christian Trautwein, * \\ and Konrad L. Streetz* \\ From the Department of Medicine III,* University Hospital \\ Aachen, Aachen, and Institute of Pathology, ${ }^{\dagger}$ University-Hospital \\ Heidelberg, Heidelberg, Germany
}

The 3,5-diethoxycarbonyl-1,4-dihydrocollidine (DDC) model leads to chronic cholestatic liver injury and therefore resembles human diseases such as sclerosing cholangitis and forms of metabolic liver diseases. The role of the interleukin-6/glycoprotein 130 (gp130) system in this context is still undefined. Therefore, conditional gp130 knockout and knockin mice were used to achieve hepatocyte-specific deletions of gp130 (gp130 $\left.{ }^{\Delta \text { hepa }}\right)$, gp130-dependent ras (gp130 and signal transducer and activator of transcription (STAT) (gp130 $\left.{ }^{\Delta h e p a s T A T}\right)$ activation. These mice were treated with a DDC-containing diet and analyzed over time. Mice deficient in hepatic gp130 and STAT signaling showed increased and earlier mortality than wild-type and $\mathrm{gp}_{130^{\Delta h e p a r a s}}$ animals. Over time, significantly more apoptosis and cholestasis became evident in gp130 $0^{\Delta \text { hepa }}$ and gp130 $0^{\Delta h e p a S t A T}$ mice. These mice also displayed increased tumor necrosis factor- $\alpha$ expression, a diminished acute-phase response (lack of STAT3 and serum amyloid $A$ activation), and enhanced immune cell infiltration in the liver. These were associated with stronger periportal oval cell activation. In addition, DDC treatment in $\mathrm{gp} 130^{\Delta \text { hepa }}$ and $\mathrm{gp} 130^{\Delta \text { hepaSTAT }}$ mice resulted in significantly stronger hepatic stellate cell activation. Long-term analysis revealed the development of severe liver fibrosis in $\mathrm{gp} 130^{\Delta \text { hepa }}$ and gp130 ${ }^{\Delta h}$ paSTAT animals, as evidenced by increased collagen accumulation. Here we demonstrate that gp130/
STAT signaling in hepatocytes provides protection in a cholestatic hepatitis mouse model. STAT3-dependent signaling pathways in hepatocytes protect from apoptosis and tissue injury, which subsequently reduce oval cell activation and prevent fibrosis progression. (Am J Pathol 2010, 176:2236-2246; DOI: 10.2353/ajpath.2010.090469)

Liver remodeling and fibrosis progression are often the result of an insufficient response of hepatocytes and biliary epithelial cells to different forms of chronic liver injury. A complex network of different liver and immune cells activates cytokines and growth factors, which trigger myofibroblasts to produce extracellular matrix proteins including collagen. Feeding mice 3,5-diethoxycarbonyl-1,4-dihydrocollidine (DDC) is a well established model to study such complex interactions in a highly relevant model of chronic cholestatic liver injury resembling certain metabolic, toxic, and cholestatic chronic liver diseases. ${ }^{1}$ Moreover, the model leads to a strong fibrotic response in the liver and can enhance the tumorigenic potential of proto-oncogenes. ${ }^{2}$ The model has also been used to study mechanisms of oval cell activation and proliferation. ${ }^{3}$

The cholestatic phenotype of the model and its underlying pathobiology have only recently been elucidated in more detail. ${ }^{1}$ DDC feeding induces sclerosing cholangitis

Supported by the Deutsche Forschungsgemeinschaft (grants 661/4-1 to K.L.S. and TRR57 to C.T.) and by the START program of the Faculty of Medicine, RWTH Aachen

W.P. and D.F.T. contributed equally to this work.

Accepted for publication January 12, 2010

Supplemental material for this article can be found on http://ajp. amjpathol.org.

Address reprint requests to Dr. Konrad Streetz, M.D., Department of Medicine III, University Hospital Aachen, Pauwelsstr. 30, 52074 Aachen, Germany. E-mail: kstreetz@ukaachen.de. 
and a biliary type of liver fibrosis, involving the secretion of proinflammatory mediators and cytokines such as tumor necrosis factor (TNF)- $\alpha$ and interleukin (IL)- $6^{4}$ and the activation of profibrogenic factors such as plateletderived growth factor and transforming growth factor- $\beta .{ }^{5}$ Together with increased biliary porphyrin secretion, these lead to activation of biliary epithelial cells, which induces a significant pericholangitis. As a consequence the secretion of toxic metabolites is impaired, further triggering hepatocyte injury and inhibiting tissue repair.

In addition, DDC feeding activates the intrahepatic stem cell compartment. Oval cells are induced and start to proliferate mainly because hepatocytes are unable to enter the cell cycle. Thereby, proinflammatory cytokines such as TNF- $\alpha^{6}$ and the related factor $L T 1 b^{7}$ are essential to trigger oval cell activation during toxic liver injury. In a different model of oval cell induction the cytokine IL-6 has also been shown to be involved in this process. ${ }^{8}$ More specifically, activation of the IL-6-dependent signal transducer and activator of transcription (STAT) 3 directly enhances the proliferation of progenitor cells, whereas activation of extracellular signal-regulated kinase (ERK) was repressive in this model.

We and others recently reported that IL-6 via gp130 triggers intracellular pathways, which are protective for hepatocytes in different models of liver injury. ${ }^{9,10}$ gp130 serves as a signal transducer for all IL-6 family members and triggers distinct pathways in the cell, leading to STAT $1 / 3$ and Ras activation. ${ }^{11}$ The relevance of these signaling cascades in hepatocytes, however, has not yet been elucidated in detail in models of chronic cholestatic liver injury. We therefore used hepatocyte-specific conditional gp130-knockout/knockin mice to test the importance of this pathway in the DDC model. We found that IL-6 via gp130-STAT3 triggers crucial downstream events in hepatocytes, which protect from liver injury and ultimately limit oval cell induction and fibrosis progression.

\section{Materials and Methods}

\section{Animal Experiments}

Hepatocyte-specific gp130-/- mice (gp130 13 hepa) were generated by breeding AlfpCre mice, ${ }^{12}$ expressing an albumin-dependent Cre-recombinase, with mice carrying a loxP-flanked gp130 ${ }^{13}$ (gp130loxP/loxP $)$ allele..$^{9}$ gp $130^{\text {loxP/loxP }}$ mice without Cre expression were used as control (wildtype) animals.

gp $130^{\Delta \text { hepaSTAT }}$ mice were generated by crossing AlfpCre gp 130 loxP/loxP with gp $130^{\Delta S T A T / \Delta S T A T}$ knockin mice expressing a truncated gp130 knockin allele that lacks the essential region for STAT1 and STAT3 activation. ${ }^{11,14}$ gp $130^{\Delta \text { hepaRas }}$ mice were generated by breeding AlfpCre gp 130 loxP/loxP with gp 130 Y757F/Y757F knockin mice. These mice carry a point mutation at tyrosine Y757 in the gp130 allele ${ }^{11}$ and are thus unable to activate gp130-dependent ras signaling. The genotypes were analyzed by PCR for AlfpCre, gp130 loxP, gp130 $13757 \mathrm{~F}$, and the gp $130^{\Delta \mathrm{STAT}}$ allele as described previously. ${ }^{14}$
At least five mice were treated and analyzed in parallel per time point. All experiments were repeated at least twice. All statistical $P$ values were calculated and proven via Student's $t$-test.

Mice were housed in 12-hour light/dark cycles with free access to food and water and were treated in accordance with the criteria of the German administrative panel on laboratory animal care. For DDC experiments 6to 8-week-old male mice were treated with standard chow containing $0.1 \%$ DDC and fed normal drinking water for up to 12 weeks. After the animals were sacrificed, blood was taken for analysis of liver transaminases. Liver samples were shock-frozen for isolation of RNA and proteins or embedded in both paraffin and Tissue-Tek Compound Medium for H\&E staining and immunohistochemical analysis.

\section{SDS-Polyacrylamide Gel Electrophoresis and Western Blotting}

Frozen liver tissues were lysed in cold-lysis buffer as described previously. ${ }^{14}$ Protein lysates were heat-denatured in double-strength SDS sample buffer containing dithiothreitol before resolution with 10\% SDS-polyacrylamide gel electrophoresis. Ponceau Red staining was used to demonstrate equal protein loading.

For primary antibody incubation, membranes were probed with anti-phosphorylated-STAT3 (Tyr-705, 9131s, Cell Signaling Technology, Danvers, MA), anti-STAT3 (STAT3, C-20, sc482, Santa Cruz Biotechnology, Heidelberg, Germany), and anti-GAPDH (4699-9555, Poole, Dorset, UK) antibodies. As a secondary antibody, horseradish peroxidase-linked anti-rabbit IgG (7074, Cell Signaling Technology) and horseradish peroxidase-linked anti-mouse IgG (sc-2005, Santa Cruz Biotechnology) were used. The antigen-antibody complexes were visualized using an ECL Chemiluminescence Kit (GE Healthcare, Little Chalfont, Buckinghamshire, UK).

\section{5-Bromo-2'-Deoxyuridine Staining}

Two hours before the animals were sacrificed, $200 \mu \mathrm{g}$ of 5-bromo-2'-deoxyuridine (BrdU) was injected intraperitoneally to label proliferating cells in the $S$ phase of the cell cycle. Staining was performed according to the Cell Proliferation Kit manual (RPN20, GE Healthcare), and BrdUnegative cells were counterstained with hematoxylin. Liver samples were analyzed by counting the number of BrdU-positive cells and the total number of cells per viewing field ( $\times 200$ magnification) for at least four animals per time point. For analysis of periportal proliferation, pictures were retrieved as described above, the periportal regions were marked manually, and counting was only performed on this regions.

\section{Terminal Deoxynucleotidyl Transferase dUTP Nick-End Labeling Staining}

Terminal deoxynucleotidyl transferase dUTP nick-endlabeling (TUNEL) staining was performed using an In Situ 
Table 1. Real-Time Primer Sequences

\begin{tabular}{ccc}
\hline $\begin{array}{c}\text { Primer } \\
\text { target }\end{array}$ & \multicolumn{1}{c}{ Sequence } & $\begin{array}{c}\text { Annealing } \\
\text { temp }\end{array}$ \\
\hline a-SMA & & $60^{\circ} \mathrm{C}$ \\
Forward & $5^{\prime}$-ATGAAGCCCAGAGCAAGAGA-3' & \\
$\quad$ Reverse & $5^{\prime}$-ATGTCGTCCAGTTGGTGAT-3' & \\
CK-19 & & $60^{\circ} \mathrm{C}$ \\
$\quad$ Forward & $5^{\prime}$-CGTACCCCCAAAGGAAGACA-3' & \\
$\quad$ Reverse & $5^{\prime}$-TCAGACCTGCGTCCCTTTTT-3' & \\
Collagen-1 $\alpha$ & & $60^{\circ} \mathrm{C}$ \\
Forward & $5^{\prime}$-GGAAACCTCTCTCGCCTCTT-3' & \\
$\quad$ Reverse & $5^{\prime}$-GAACAGGGTGTTCCTGAGA-3' & \\
GAPDH & & $60^{\circ} \mathrm{C}$ \\
Forward & $5^{\prime}$-TGTTGAAGTCACAGGAGACAACCT-3' & \\
$\quad$ Reverse & $5^{\prime}$-AACCTGCCAAGTATGATGACATCA-3' & \\
IL-6 & & $59^{\circ} \mathrm{C}$ \\
$\quad$ Forward & $5^{\prime}$-CCGGAGAGGAGACTTCACAG-3' & \\
$\quad$ Reverse & $5^{\prime}$-TCCACGATTTCCCAGAGAAC-3' & \\
TNF- $\alpha$ & & $59^{\circ} \mathrm{C}$ \\
$\quad$ Forward & $5^{\prime}$-CCCAGGTATATGGGCTCATACC-3' & \\
$\quad$ Reverse & $5^{\prime}$-GCCGATTTGCTATCTCATACCAGG-3' & \\
TGF- $\beta_{1}$ & & $58^{\circ} \mathrm{C}$ \\
Forward & $5^{\prime}$-GACCCTGCCATATTTGGA-3' & \\
Reverse & $5^{\prime}$-GCCCGGGTTGTGTTGGT-3' & \\
\hline & &
\end{tabular}

Cell Death Detection Kit, POD (Roche Diagnostics, Mannheim, Germany) according to the instructions of the manufacturer as described previously. ${ }^{9}$

\section{Quantitative Real-Time PCR}

Total RNA from frozen liver was isolated and treated with DNase I (Invitrogen, Karlsruhe, Germany) before cDNA was generated by reverse transcription with $100 \mathrm{ng}$ of random hexamer (Invitrogen), $250 \mu \mathrm{mol} / \mathrm{L}$ dNTPs (Invitrogen), and 200 units of M-MLV Reverse Transcriptase (Invitrogen) in $1 \times$ reverse transcriptase buffer for 1 hour at $37^{\circ} \mathrm{C}$. Real-time PCR was performed by using a 7300 Real-Time PCR System (Applied Biosystems, Foster City, $\mathrm{CA}$ ) and SYBR GreenER qPCR SuperMix (Invitrogen). The expression levels of the different genes were normalized with the levels of GAPDH. To monitor the specificity, the final PCR products were analyzed by melting curves and electrophoresis. The primer sequences used are listed in Table 1.

\section{Histology, Sirius Red Staining}

Liver samples were either snap-frozen in OCT compound or fixed in $3.5 \%$ formaldehyde, embedded in paraffin, cut, and stained with H\&E. Pictures were taken using an Axio-Imager Z1 (Carl Zeiss, Jena, Germany) for each time point per genotype.

For Sirius red staining the sections were incubated in the Sirius red staining solution for 1 hour. Thereafter the slides were incubated in $0.1 \mathrm{~mol} / \mathrm{L} \mathrm{HCl}$ for 5 minutes, treated with an ascending ethanol series, and finally incubated in Roti-Histol (Roth, Karlsruhe, Germany) and covered with Roti-Histokit (Roth). The sections were analyzed under polarized light. Photomicrographs of Sirius red-positive areas taken in a $\times 200$ magnification were analyzed via color error measurement using the open source software ImageJ. Thereby collagen filaments were morphometrically analyzed and used for the calculation of collagen per area field.

\section{Immunofluorescence and Immunohistochemistry}

Cryopreserved liver tissues were fixed in 4\% paraformaldehyde (Roth), washed in PBS containing $0.02 \%$ sodium azide (Roth), and blocked using $2 \%$ bovine serum albumin in PBS-azide. $\mathrm{CD}^{+}$cells were detected using a direct fluorescein isothiocyanate-labeled antibody (clone GK 1.5, Molecular Probes/Invitrogen, Karlsruhe, Germany). For the detection of CD11b (BD Bioscience, Heidelberg, Germany), cytokeratin (CK)-8 (keratin K8, Ks 8.7, Progen catalog no. 61038), CK-19 (Santa Cruz Biotechnology), Sca-1 (Ly-6A/E, catalog no. 553333, BD Pharmingen), and ubiquitin (Z0458, DAKO, Hamburg, Germany) positive cells, we used secondary antibody detection systems. Tissues were fixed in ice-cold acetone and blocked with a 1:5 dilution of blocking reagent (Promega, Mannheim, Germany) and detected via an anti-rabbit Alexa 488-labeled secondary antibody (Molecular Probes/Invitrogen). Ubiquitin staining was visualized using a horseradish peroxidase-labeled secondary anti-rat antibody.

\section{Primary Hepatocyte Isolation}

Mice were anesthetized with ketamine/xylazine and 300 $\mathrm{IU}$ of heparin was injected intraperitoneally. The abdominal wall was opened, the inferior vena cava was prepared and cannulated, and perfusion with hepatocyte isolation buffer was started. Hepatocyte isolation buffer (HB) containing $0.15 \mathrm{~mol} / \mathrm{L} \mathrm{NaCl}, 6 \mathrm{mmol} / \mathrm{L} \mathrm{KCl}, 5 \mathrm{mmol} / \mathrm{L}$ glucose, $0.02 \mathrm{~mol} / \mathrm{L} \mathrm{HEPES}$, and $2.5 \mathrm{~mol} / \mathrm{L} \mathrm{NaHCO}_{3}$ was prepared ( $\mathrm{pH} 7.4)$. First, HB mixed with $1 \mathrm{mmol} / \mathrm{L}$ EDTA was perfused. The second perfusion was performed with $\mathrm{HB}$ containing $2 \mathrm{mmol} / \mathrm{L} \mathrm{CaCl}_{2}$ and $0.1 \%$ collagenase. After perfusion the liver was carefully harvested, minced in $10 \mathrm{ml}$ of Williams' Eagle's media (PAA Laboratories $\mathrm{GmbH}$, Cölbe, Germany), filtered through $70-\mu \mathrm{m}$ cell strainer (BD Bioscience), and immediately stored on ice. Cells were then plated on collagen-covered wells in HepatoZYME-SFM (Invitrogen, Karlsruhe, Germany). After 4 hours medium was changed, and cells were stimulated with recombinant TNF- $\alpha$ (Invitrogen).

\section{Results}

\section{Enhanced Mortality and Cholestasis after DDC Treatment in Mice Lacking Hepatocellular gp130 and gp130/STAT Activation}

To investigate the relevance of IL-6/gp130-dependent signaling in hepatocytes during chronic cholestatic liver injury we treated wild-type (gp130 $10 \times \mathrm{P} / \mathrm{loxP})$ and hepatocyte-specific gp130 knockout mice (gp130 ${ }^{\text {hepa }}$ ) with a $0.1 \%$ DDC-containing diet. Of the wild-type mice, $80 \%$ survived the first 6 weeks of DDC treatment, whereas 
A

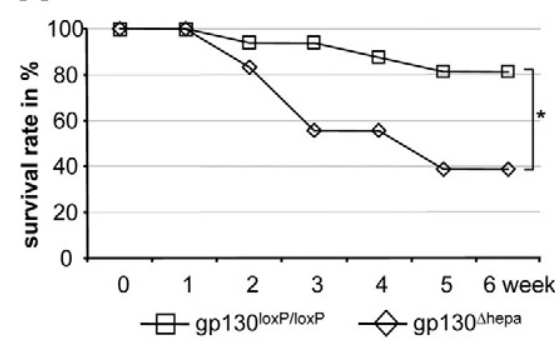

C

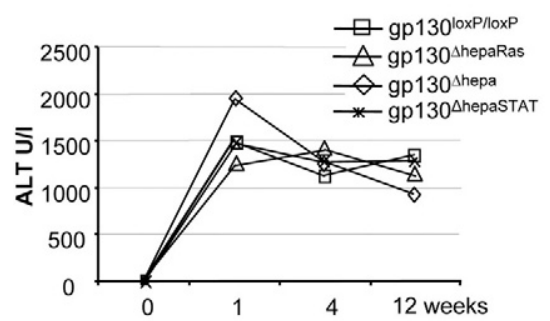

B

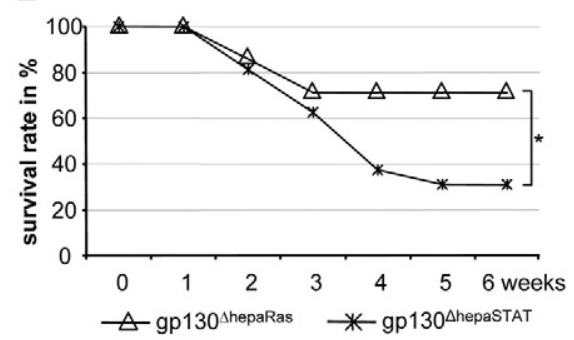

D

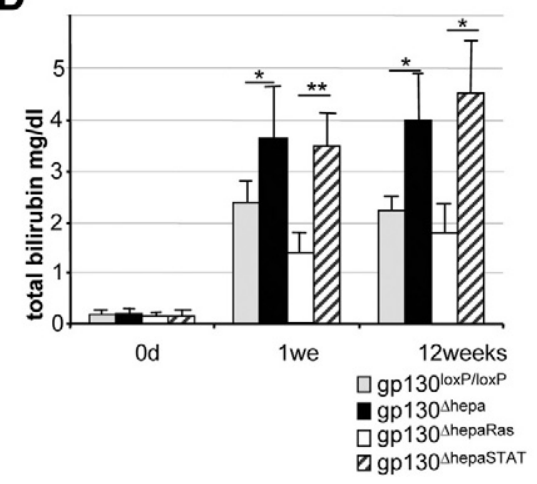

Figure 1. Lower survival and enhanced cholestasis in mice with abolished hepatocellular gp130/STAT signaling after DDC treatment. A: Mice were fed with $0.1 \%$ DDC to induce chronic cholestatic liver injury. DDC treatment triggered death of experimental animals in all treated groups over time. gp $130^{\text {loxp/loxp }}$ mice showed an overall survival of $81 \%$. This rate significantly dropped to $38 \%$ in the gp $130^{\Delta \text { hepa }}$ group $\left({ }^{*} P<\right.$ $0.05)$. B: Survival rates after DDC treatment were $72 \%$ in gp $130^{\text {thepaRas }}$ mice compared with $30 \%$ in gp $130^{\Delta \text { hepaSTAT }}$ mice $\left({ }^{*} P<0.05\right)$. Sixteen mice per group were included in either survival analysis. C: Alanine aminotransferase (ALT) serum levels were determined 1,4 , and 12 weeks after DDC treatment was started. Transaminases increased rapidly in all treatment groups and remained at a significantly higher level throughout the experiment. D: Total bilirubin serum levels were measured after 1 and 12 weeks of DDC treatment $\left({ }^{*} P<0.05 ;{ }^{* * *} P<0.01\right)$ more than $60 \%$ of the gp $130^{\text {hepa }}$ animals died during this period (Figure 1A). To dissect gp130-dependent intracellular signaling pathways we treated mice with either impaired gp130-dependent ras (gp130 ${ }^{\text {hepaSTAT }}$ ) or STAT (gp130 ${ }^{\text {hepaRas}}$ ) signaling in hepatocytes with the DDC diet. These experiments demonstrated that impaired survival after DDC feeding is linked to the lack of hepatocellular gp130dependent STAT3 activation, whereas gp130 ${ }^{\text {hepaRas }}$ animals displayed a survival curve similar to that of wild-type mice (Figure 1B).

Biochemical analysis of liver transaminases revealed a rapid and strong increase in all groups after DDC feeding (Figure 1C). Serum bilirubin levels increased in all four groups after DDC feeding as well but were significantly higher in gp130 13 hepa and gp130 13 hepaSTAT mice, the groups with the highest mortality (Figure 1D).

\section{Lack of Acute-Phase Induction and Altered Inflammatory Response in Mice without gp130 and STAT3 Activation in Hepatocytes}

DDC treatment is known to induce a significant inflammatory response. We thus determined hepatic expression levels of the proinflammatory cytokines TNF- $\alpha$ and IL-6 by real-time PCR. TNF- $\alpha$ was induced about 18fold in wild-type and gp130 13 heparas mice, whereas gp130 13 hepa and gp130 cantly stronger (up to 50-fold) response after 2 weeks of treatment (Figure 2A). TNF- $\alpha$ expression remained elevated compared with that in the untreated animals in all groups after 12 weeks of the DDC diet. At this time point significantly higher TNF- $\alpha$ expression levels were found in gp $130^{\text {hepasTAT }}$ than in wild-type mice. IL-6 levels were 30- to 40-fold induced 2 weeks after treatment. At this time point $\mathrm{gp} 130^{\Delta \text { hepaRas }}$ mice displayed significantly lower IL-6 levels than gp130 13 hepa and gp130 1 hepaSTAT animals (Figure 2B). IL-6 levels remained moderately elevated after 12 weeks of treatment without significant differences between the groups.

The acute-phase response (APR) induction as a major unspecific defense mechanism is one of the main consequences of IL-6 activation in hepatocytes. ${ }^{15}$ We thus analyzed hepatic STAT3 phosphorylation (Figure 2C) and the induction of the APR marker gene serum amyloid A-2 (Figure 2D). STAT3 was readily phosphorylated in control and gp130 13 hepaRas mice after 2 and 12 weeks of DDC treatment. However its activation was blunted in gp130 13 hepa and gp130 STAT3-phosphorylation only became evident at a significant strength in hepatocytes of gp130-competent mice and was absent in cholangiocytes and biliary epithelial cells of either genotype (Supplemental Figure S1, see http://ajp.amjpathol.org). Differences in the level of STAT3 phosphorylation were not due to changes in total STAT3 protein levels over time as those remained unchanged (Figure 2E). Interestingly, we observed basal STAT3 phosphorylation in untreated gp $130^{\text {AhepaRas }}$, which can be explained by the already described intrinsic hyperactivation of the STAT3 pathway in these mice. ${ }^{14}$

Next, we were interested in studying whether these strong differences in APR induction have an impact on immune cell activation in the livers of these animals. We analyzed hepatic infiltration of $\mathrm{CD}^{+}{ }^{+} \mathrm{T}$-cells, neutrophils (Ly6G), and macrophages (CD11b) in DDC-treated mice (Figure 3, A-C, Supplemental Figure S2, see http://ajp. amjpathol.org). Mice deficient in gp130 and gp130/STAT activation displayed an overall stronger immune cell recruitment. Neutrophil infiltration was significantly less in wild-type and gp130 13 hepaRas mice, whereas macrophages were significantly more present, especially in 
A

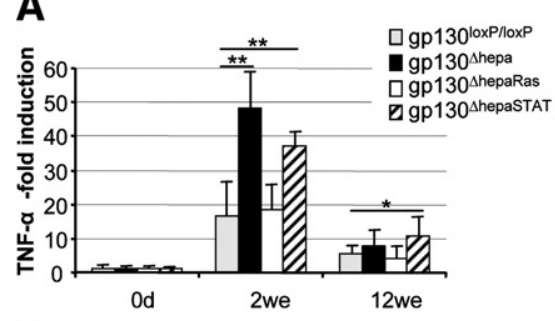

C

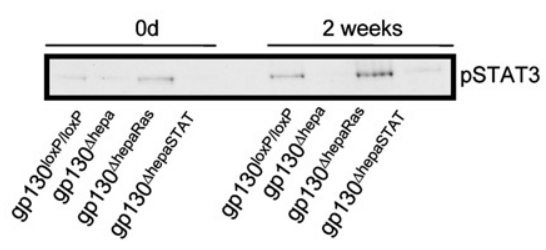

B

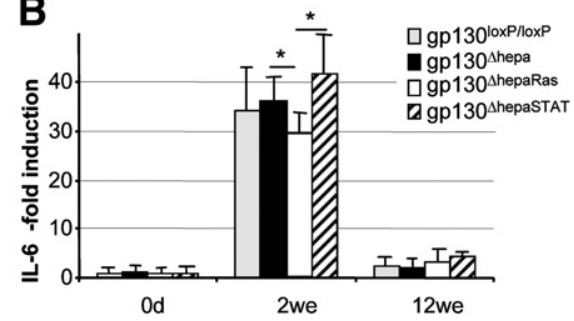

D

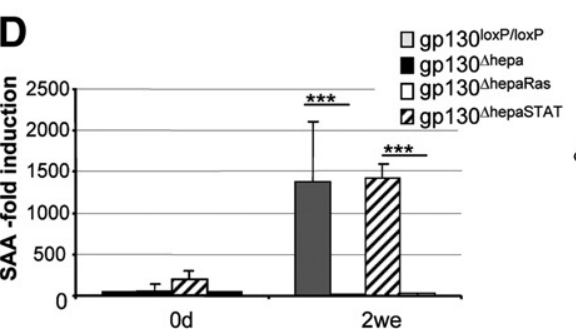

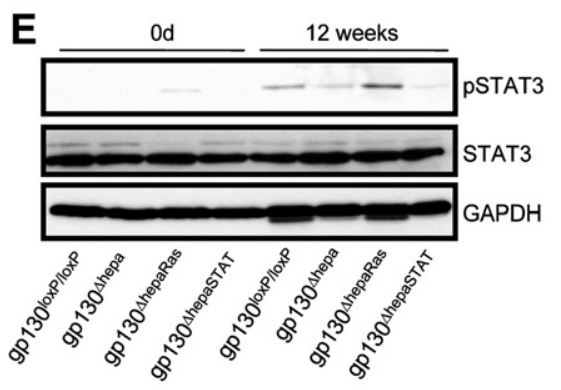

Figure 2. Enhanced expression of inflammatory cytokines and blunted APR in gp $130^{\Delta \text { hepa }}$ and gp $130^{\Delta \text { hepasTAT }}$ animals. A and B: Hepatic TNF- $\alpha$ (A) and IL-6 (B) mRNA expression levels were determined by quantitative real-time PCR. RNA was isolated from mice 2 and 12 weeks after DDC treatment. The fold induction of cytokine mRNA levels is displayed ( ${ }^{*} P<0.05$; $\left.{ }^{* *} P<0.01\right)$. C: STAT phosphorylation was determined by Western blot analysis of whole liver cell extracts derived from mice treated 2 weeks with DDC using a phospho-STAT3 (pSTAT3)-specific antibody. D: Serum amyloid A (SAA) mRNA levels were determined by quantitative real-time PCR after 2 weeks of DDC treatment. The fold induction of mRNA levels is shown (*** $P<0.001)$. E: TAT phosphorylation and expression of STAT3 protein were analyzed by Western blots using whole liver cell extracts derived from mice treated 12 weeks with DDC.

gp130 13 hepaSTAT mice. In addition, there was a clear trend in the amount of infiltrating $\mathrm{CD}^{+}$cells showing higher cell numbers in gp130 13 hepa and gp130 13 hepaSTAT mice compared with that in wild-type and gp130 13 hepaRas animals.

\section{Enhanced Apoptosis and Periportal Proliferation

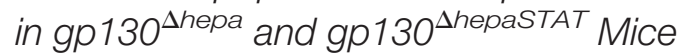

Because the gp130/STAT3 axis can provide antiapoptotic signals in hepatocytes, ${ }^{9}$ we next studied the impact of DDC feeding on apoptosis. TUNEL stainings of liver samples were performed before and 2 weeks after DDC treatment (Figure 4A) and showed increasing numbers of TUNEL-positive cells in all animals. The apoptosis rates were 0.6 to $1 \%$ in wild-type and gp $130^{\text {AhepaRas }}$ mice after 2 weeks of treatment. In contrast, a significant stronger rate of TUNEL-positive cells was evident in the gp $130^{\Delta \text { hepa }}$ and gp $130^{\Delta \text { hepaSTAT }}$ groups at the 2-week time point. The apoptosis rate in these animals was 4- to 6-fold enhanced compared with that in wild-type and gp130 13 hepaRas mice (Figure 4B). We thus investigated whether TNF- $\alpha$-induced cell injury could be linked to this observation. Primary hepatocytes isolated from DDCtreated gp130 13 hepa and gp $130^{\Delta \text { hepaSTAT }}$ mice showed a higher susceptibility against TNF- $\alpha$-induced cell death (Supplemental Figure S3, see http://ajp.amjpathol.org).

Next BrdU-labeling assays were performed to see whether a lack of gp130-STAT signaling also had an impact on the hepatic proliferative response. Interestingly, the amount of BrdU-positive hepatocytes was not different among the four groups. However, a significantly stronger proliferation rate was evident in the periportal regions of gp $130^{\Delta \text { hepa }}$ and gp $130^{\Delta \text { hepaSTAT }}$ livers (Figure 4, C-E).

\section{Strong Periportal Proliferation and Oval Cell Response in Mice with a Lack of Hepatic gp130/STAT3 Activation}

H\&E stainings revealed the development of severe morphological changes in the liver architecture of DDC-fed mice (Supplemental Figure S4, A and B, see http://ajp.amjpathol. org) starting shortly after DDC treatment. Hepatocytes displayed enhanced eosinophilia, periportal infiltrates became evident, and morphologically small-appearing cells with scant cytoplasm were clustering periportally. The first signs of small duct-like structure formation indicated the initiation and progression of cholestatic sclerosis, which is intrinsic for the DDC model, ${ }^{1}$ already in the early phase of treatment. Mallory-Denk bodies, which have been described in the DDC model ${ }^{16}$ could be detected uniformly at the 12-week time point throughout the groups (Supplemental Figure S4C, see http://ajp.amjpathol.org).

We thus aimed to analyze whether cells in the periportal region share the characteristics of oval cells as are known for mice treated with DDC. Oval cells are described as progenitor cells with a potential to differentiate into biliary epithelial cells and hepatocytes. They express a cytokeratin marker and are reported to carry stem cell-specific antigens. We thus analyzed the expression of CK-19 and CK-8 (Figure 5, A and B), both commonly expressed by biliary epithelial cells and their progenitors and of the stem cell marker Sca-1 (Figure 5C). We uniformly observed enhanced staining of all three markers in gp $130^{\text {hepa }}$ and gp $130^{\text {hepa/STAT }}$ mice compared with that in wild-type and gp $130^{\text {hepaRas }}$ mice after 12 weeks of DDC treatment (for further quantification and detailed depiction, Supplemental Figure S5, see http://ajp.amjpathol.org). 
A

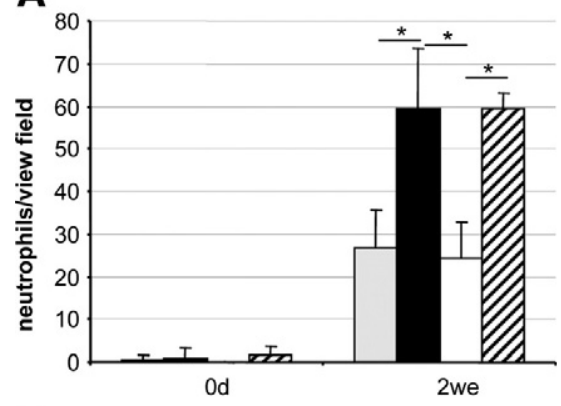

B

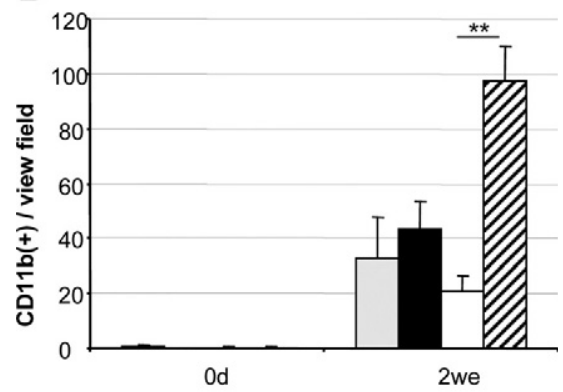

c

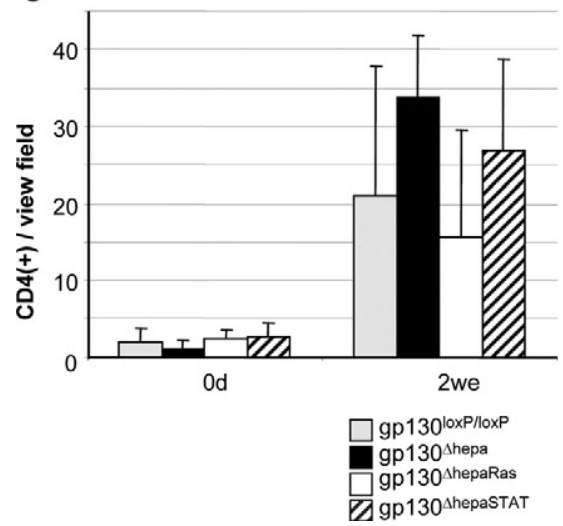

Figure 3. Altered immune cell activation induced by DDC treatment. AntiLy6G (A) for neutrophils, anti-CD11b (B), and anti-CD4 (C) stainings were performed using liver tissue sections derived from mice treated for 2 weeks with DDC. A quantitative analysis of positive stained cells per view field is depicted $\left(* P<0.05 ;{ }^{* *} P<0.01\right)$. At least 10 view fields of four livers per time point were included in this analysis. Anti-Ly $6 \mathrm{G}^{+}$, anti$\mathrm{CD}_{11} \mathrm{~b}^{+}$, and anti-CD $4^{+}$stainings are provided in Supplemental Figure S2 (see http://ajp.amjpathol.org).

\section{Fibrosis Progression Inversely Correlates with STAT Activation in Hepatocytes}

Histomorphological analysis (Supplemental Figure S3B, see http://ajp.amjpathol.org) further revealed the beginning of portoportal bridging, indicating the progression of liver fibrosis in DDC-treated mice. We therefore aimed to quantify the degree of fibrosis and the related activation of matrix-producing hepatic stellate cells.

First, we studied the expression of $\alpha$-smooth muscle actin ( $\alpha$-SMA), a marker for activated stellate cells. Morphometric analysis of immunohistochemical $\alpha$-SMA stainings showed increased stellate cell activation in gp $130^{\Delta \text { hepa }}$ and gp $130^{\Delta \text { hepaSTAT }}$ livers already 2 weeks after DDC feeding (Figure 6A, Supplemental Figure S6A, see $h$ ttp://ajp.amjpathol.org). These results were further confirmed by $\alpha$-SMA real-time PCR analysis (Figure 6B). Transforming growth factor- $\beta$, as another important profibrogenic cytokine, was found to be regulated accordingly (Figure 6C).

Next, Sirius Red stainings were performed and morphometrically analyzed. A 2.5- to 3-fold increase in collagen staining was evident in the gp130 ${ }^{\text {hepa }}$ and gp130 13 hepaSTAT groups compared with wild-type and gp130 13 hepaRas animals (Figure 6D, Supplemental Figure S6B, see http://ajp.amjpathol.org). The data showing stronger collagen staining were further supported by the collagen- $1 \alpha$ mRNA results. Here, an approximately twofold stronger collagen- $1 \alpha$ mRNA level was found in the two groups with a lack of hepatocyte-specific gp130STAT activation (Figure 6E, Supplemental Figure S6B, see http://ajp.amjpathol.org).

\section{Discussion}

IL-6 via gp130 in hepatocytes controls the acute-phase response, and in recent years it has become evident that this pathway is also important during acute liver injury. We and others could demonstrate a protective effect of gp130-dependent signaling, mainly mediated via STAT3 activation, in hepatocytes ${ }^{17,18}$ but also in other cells, eg, immune cells. ${ }^{19}$ At present, most studies have focused on mechanisms of acute liver injury, and only a few were designed to resolve the role of the IL-6/gp130 system during chronic liver injury. ${ }^{20}$ Although studies have been undertaken in IL-6 knockout mice, those data cannot uniformly explain all disease mechanisms of chronic cholestatic liver injury, ${ }^{6,21}$ because gp130 is used redundantly ${ }^{22}$ by various cytokines. Therefore, in our present work we aimed to better characterize the role of hepatic gp130/STAT3 activation during chronic cholestatic liver injury.

DDC feeding triggers cholestatic liver damage, which leads to injury of both hepatocytes and biliary epithelial cells, thus resembling in many aspects certain human chronic liver diseases. ${ }^{1}$ These include forms of end-stage metabolic liver diseases as well as primary and secondary sclerosing cholangitis. Based on current knowledge the DDC model proceeds in two phases. The early phase is dominated by the rapid onset of hepatocellular liver injury involving apoptosis (Figure 3, B and C) and the induction of ductular proliferates including the activation of the oval cell compartment. During this phase the animals also develop rapid and sustained jaundice. At the second later stage the deleterious effect of chronic cholestasis becomes evident, which triggers transformation of hepatic stellate cells into myofibroblasts and contributes to the progression of liver fibrosis.

Our data support the fact that DDC treatment triggers an early and strong hepatic inflammatory response, as evidenced by the expression of IL-6 and TNF- $\alpha$ (Figure 2, $A$ and $B$ ). This causes a selective induction of the APR in wild-type and gp $130^{\Delta h e p a R a s}$ animals where STAT3 signaling is active. Earlier results demonstrated that STAT3 induces an antiapoptotic response in hepatocytes, eg, 
A
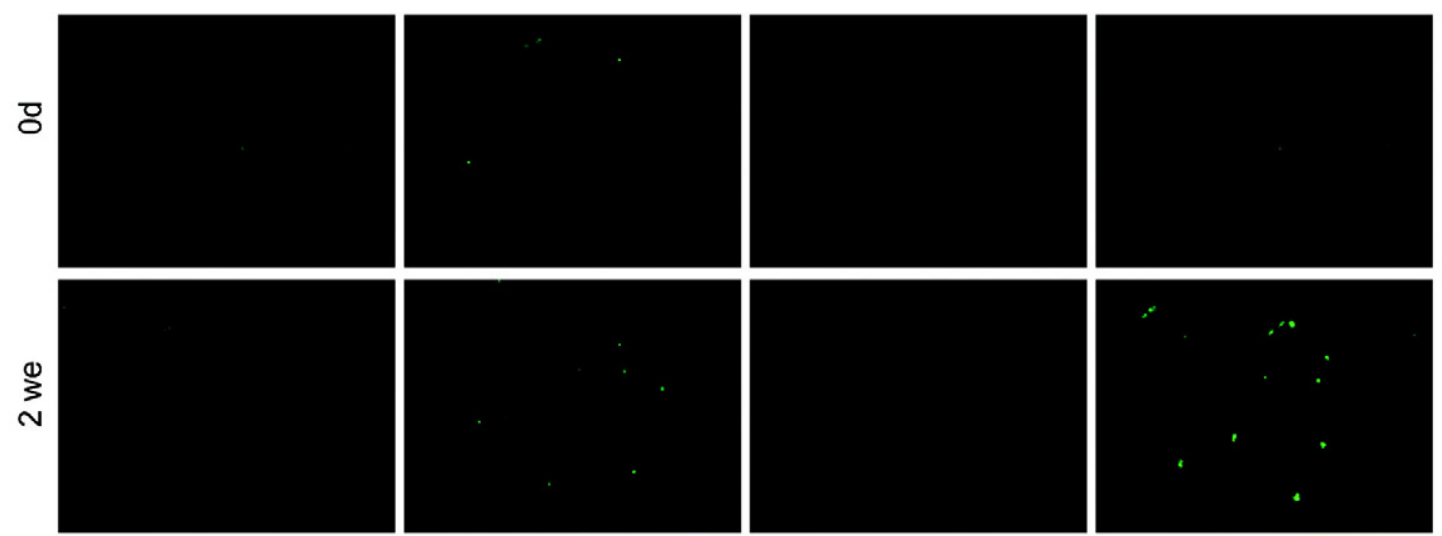

gp130'loxP/loxP

gp130 13 hepa

gp130دhepaRas

gp130 1 hepaSTAT

B ஃ

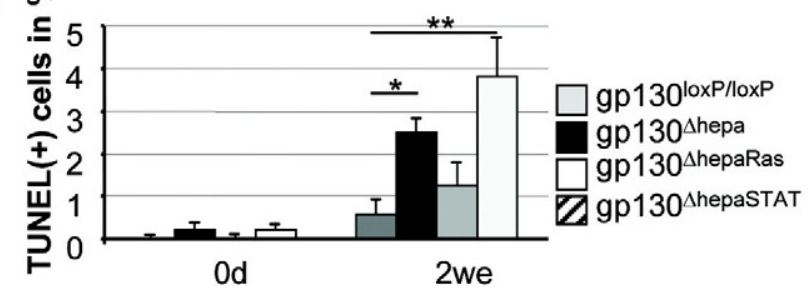

C

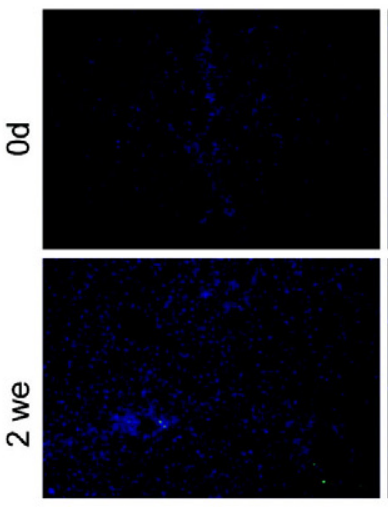

gp130loxP/loxP
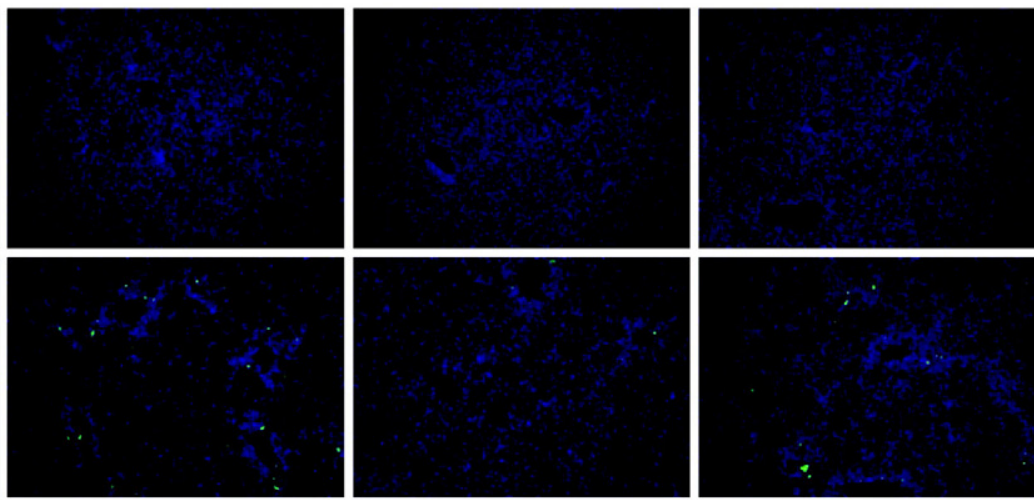

gp130 13 hepa

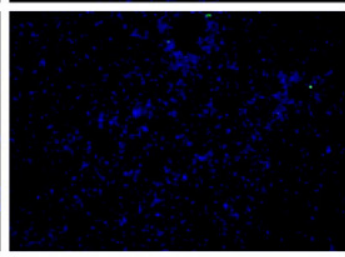

gp130 ${ }^{\text {AhepaRas }}$

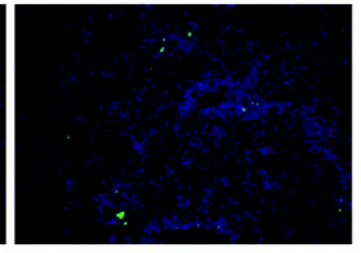

gp130 ${ }^{\Delta h e p a S T A T}$

\section{D}

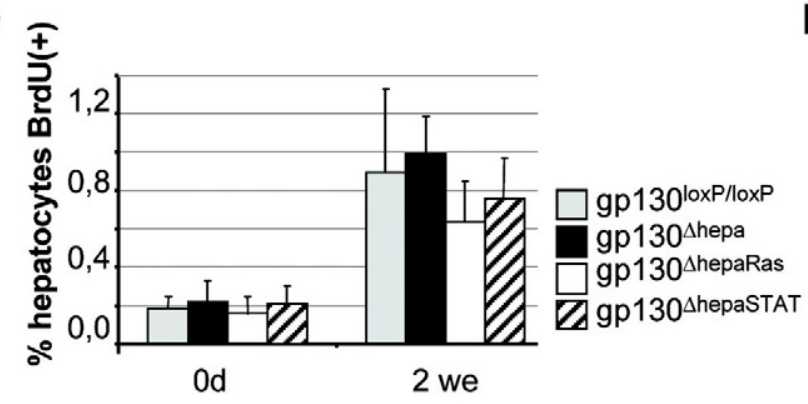

E$$
\text { 章 }
$$

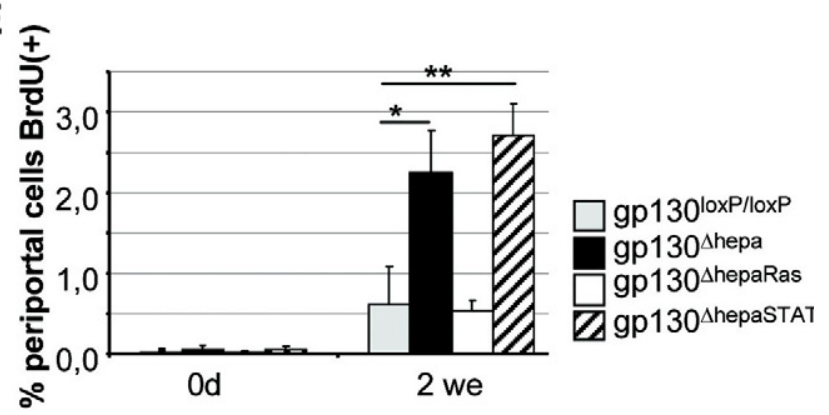

Figure 4. Apoptosis and cell proliferation depend on hepatic gp130 and STAT activation. A: Apoptotic cells were analyzed by TUNEL staining (green) in livers of the four treatment groups before and after 2 weeks of DDC treatment as indicated. Representative pictures are shown for each time point. B: Statistical analysis of TUNEL-positive cells in livers after DDC treatment $\left({ }^{*} P<0.05 ;{ }^{* * *} P<0.01\right)$. At least 10 view fields of four livers per time point were included in this analysis. C: Liver cell proliferation was analyzed by BrdU uptake in livers of DDC-fed mice before and 2 weeks after treatment. Anti-BrdU antibodies were labeled with Alexa 488 (green). D and E: Statistical analysis of BrdU-positive cells before and 2 weeks after DDC treatment are displayed $\left({ }^{*} P<0.05 ;{ }^{* *} P<0.01\right)$. At least 10 view fields of four livers per time point were included in this analysis. Proliferating hepatocytes (D) and cells in periportal areas (E) were analyzed separately.

via the up-regulation of genes such as B-cell lymphoma-extra large $(\mathrm{Bcl}-\mathrm{xL})$ and $\mathrm{c}-\mathrm{Flip} .^{23}$ This can explain why we observed more apoptosis and a greater susceptibility against TNF- $\alpha$-induced toxicity in hepato- cytes lacking STAT activation (Supplemental Figure S3, see http://ajp.amjpathol.org).

Besides the direct injury of hepatocytes, chronic cholestasis induced by DDC treatment probably also con- 


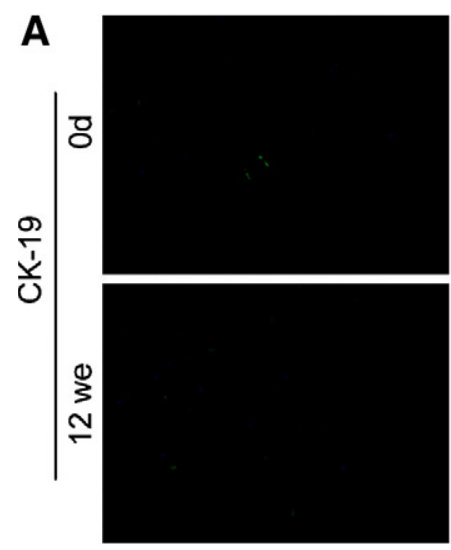

gp130loxP/loxP

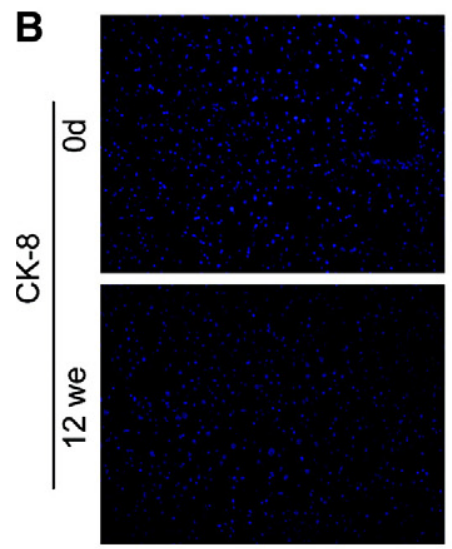

gp130 $0^{\text {loxPlloxP }}$

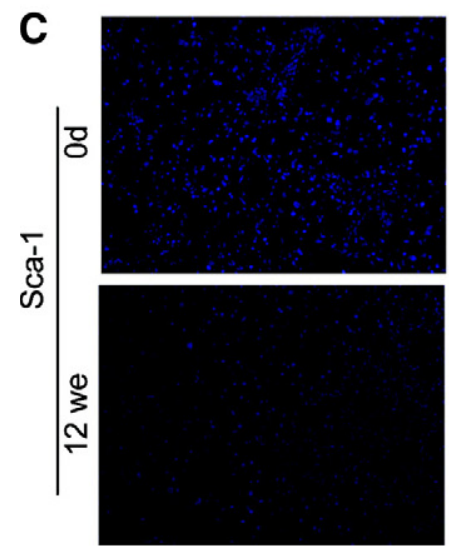

gp130 $0^{\operatorname{loxP} P / \operatorname{lox} P}$

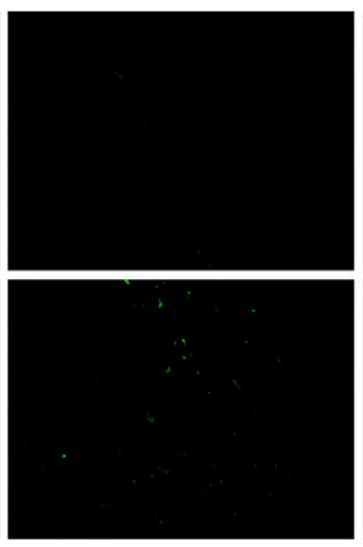

gp130 13 hepa
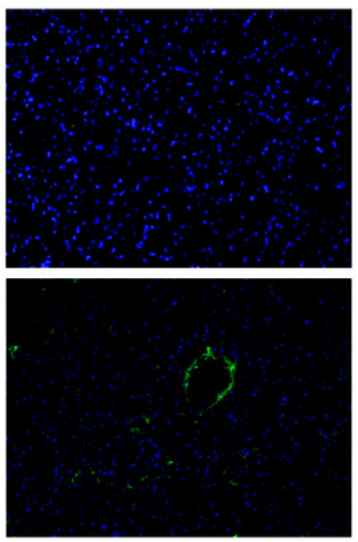

gp $130^{\text {Ahepa }}$

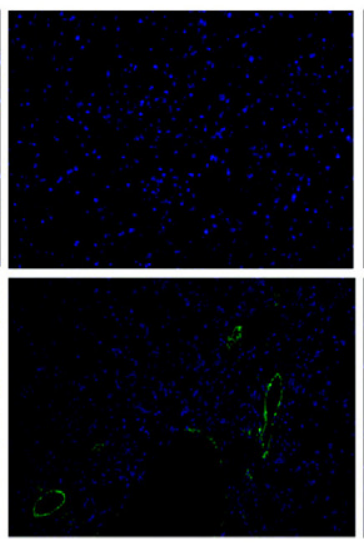

gp130 1 hhepa

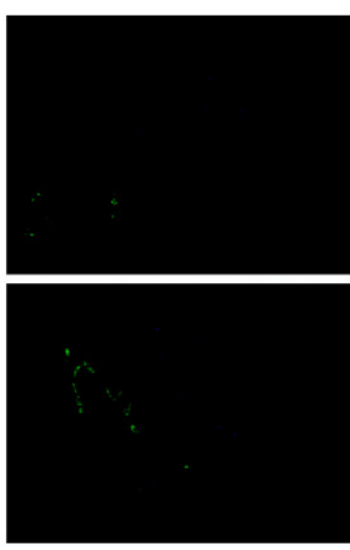

gp130 1 hepaRas
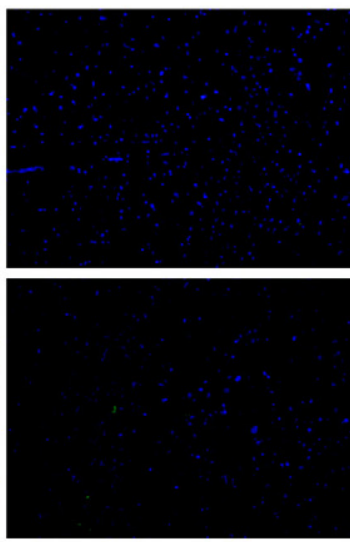

gp130 1 hepaRas

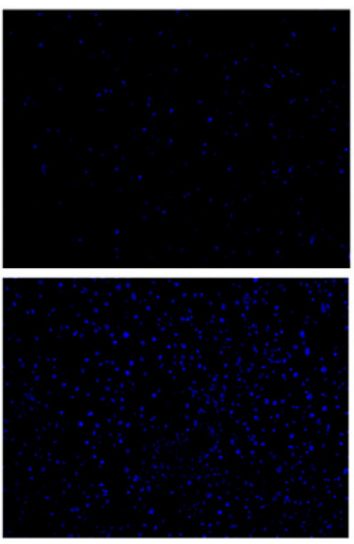

gp130 13 hepaRas

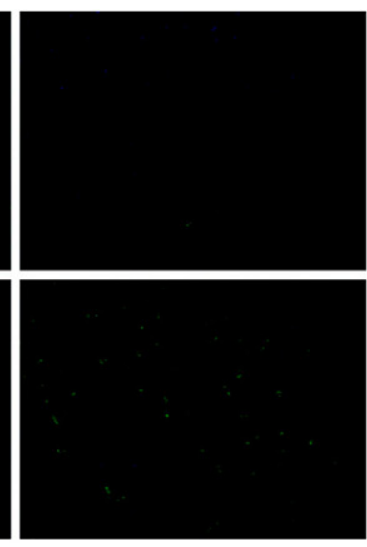

gp130 1 hepaSTAT
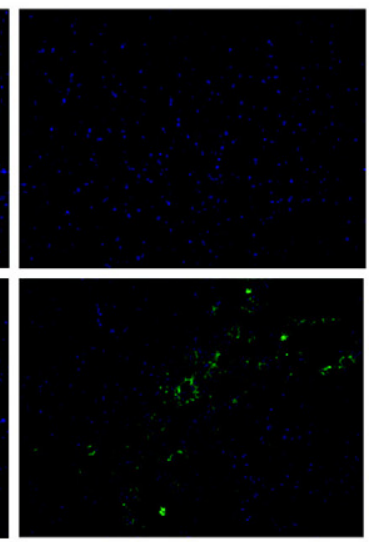

gp130 ${ }^{\Delta h e p a S T A T}$

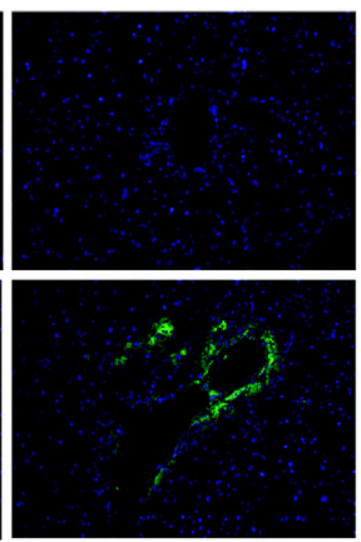

gp130 1 hepaSTAT

Figure 5. Progenitor cell activation after DDC treatment. Immunohistochemical stainings for CK-19 (A), CK-8 (B), and Sca-1 (C) were performed in liver sections derived from mice treated for 12 weeks with DDC. Anti-CK-19 labels common biliary epithelial and progenitor cells activated during chronic liver injury. Note the small duct-like structures, which stain positive. Anti-CK-8 predominantly stains intermediary filaments, ductular structures, and small cells. Anti-Sca-1-positive cells are believed to represent progenitor cells with a stem cell-like character. A further quantification of the presented stainings is given in Supplemental Figure 5 (see bttp://ajp.amipathol.org).

tributes to the severe phenotype of these animals, which are not protected by gp130/STAT signaling any more. Bile acids and other components of the bile fluid are toxic during cholestatic conditions. They have recently been shown to induce apoptosis and to antagonize protective IL-6 signals in hepatocytes. ${ }^{24,25}$ In addition, the death ligand tumor necrosis factor-related apoptosis-inducing ligand and its receptor DR5 are known to be up-regulated during cholestasis. ${ }^{26}$ Thus, this pathway could be directly involved in triggering apoptosis in the liver of DDCtreated animals, especially if antiapoptotic pathways are inhibited.

Infiltrating neutrophils and macrophages, as well as resident Kupffer cells are an important source for inflammatory cytokines, which are involved in triggering organ injury. ${ }^{23}$ In control and gp130 ${ }^{\text {hepaRas }}$ animals lower 
A
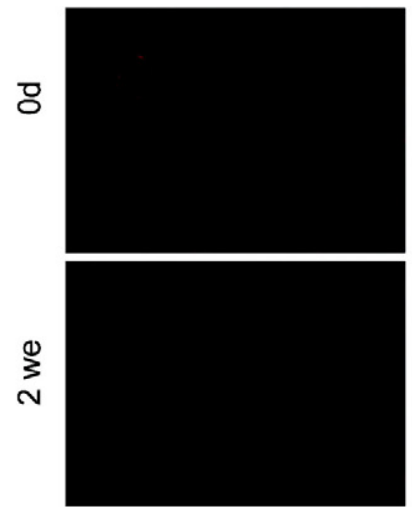

gp130loxP/loxP
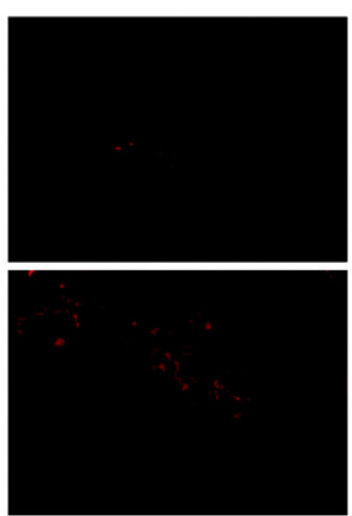

gp130 13 hepa
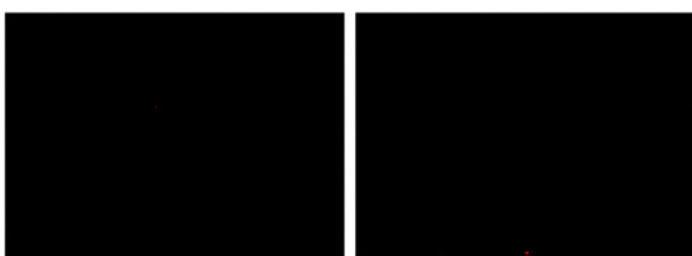

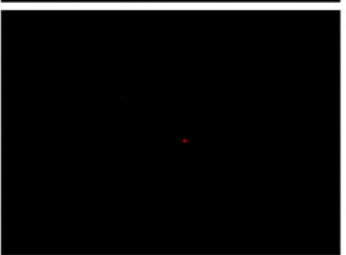

gp130 hhepaRas

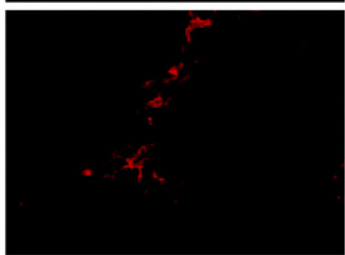

gp130 1 hepaSTAT
B

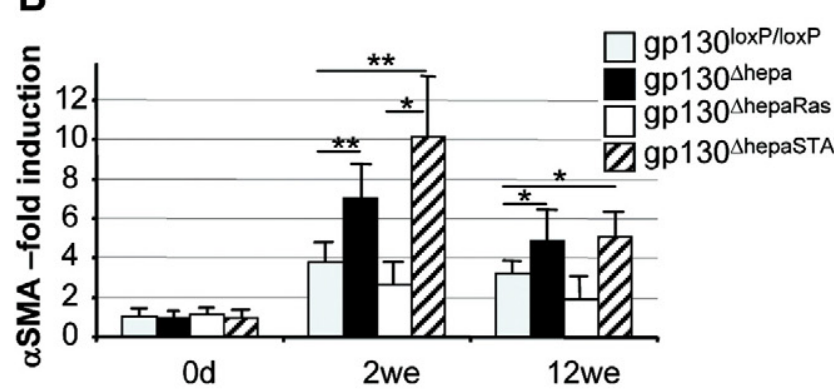

D
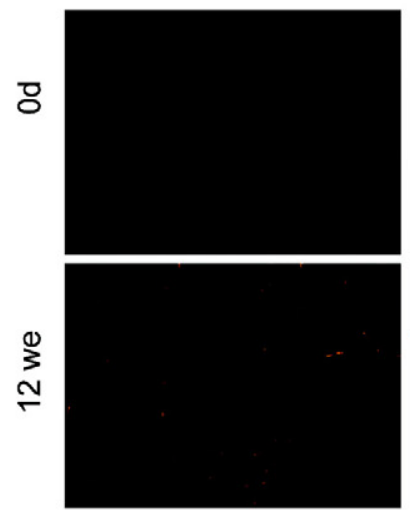

gp130loxP/loxP

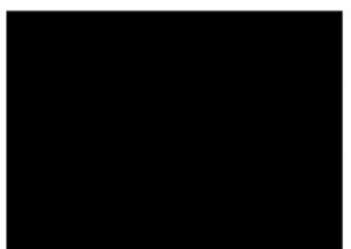

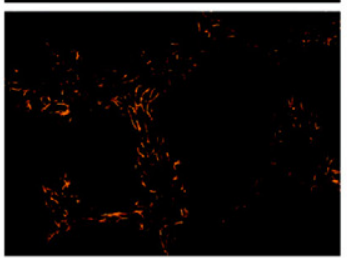

gp130 13 hepa

E

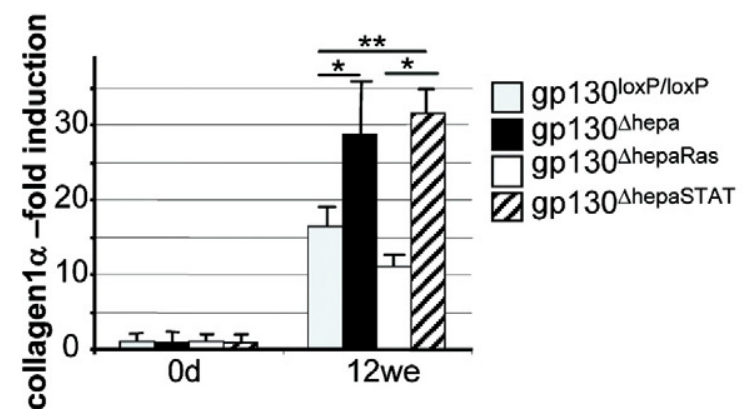

TNF- $\alpha$ expression was detected compared with that in the two other groups. TNF- $\alpha$-dependent gene transcription via nuclear factor- $\kappa \mathrm{B}$ in hepatocytes and nonparenchymal cells plays an important role in triggering the expression of cytokines and chemokines but also the activation of hepatic stellate cells. ${ }^{24,25}$ In gp $130^{\text {hepa }}$ and gp130 13 hepaSTAT animals we thus found stronger hepatic

C

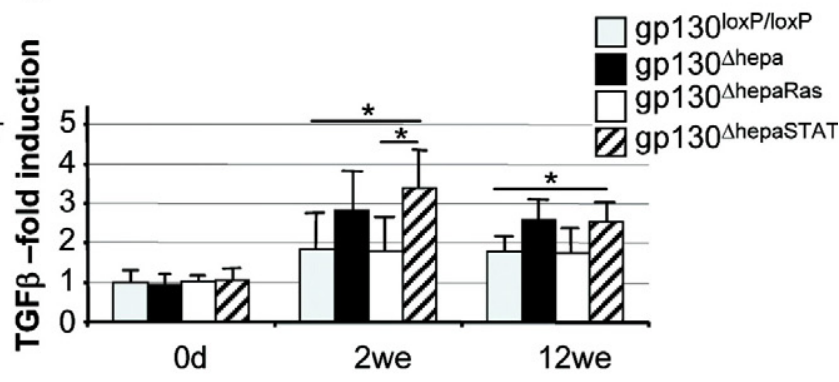

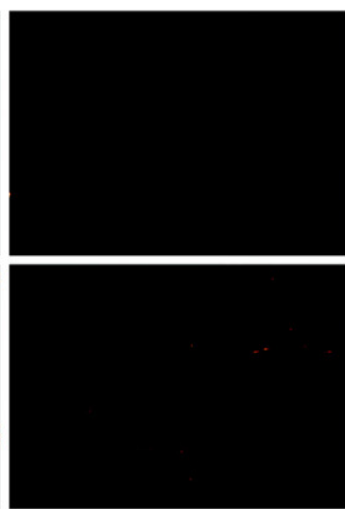

gp130 ${ }^{\text {hepaRas }}$
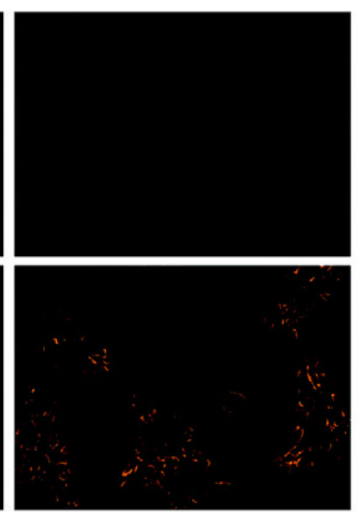

gp130 13 hepasTAT
Figure 6. Increased stellate cell activation and fibrosis progression in gp130 $0^{\Delta \text { hepa }}$ and gp $130^{\Delta \text { hepaSTAT }}$ mice after DDC treatment. A: Immunofluorescence analysis of $\alpha$-SMA expression in livers after 2 weeks of DDC treatment. The staining marks perivascular cells and enhanced staining of cells in periportal areas of the gp $130^{\Delta \text { hepa }}$ and gp $130^{\Delta \text { hepaSTAT }}$ groups. B and C: Hepatic $\alpha$-SMA mRNA and transforming growth factor- $\beta$ expression levels were determined by quantitative real-time PCR. RNA was isolated from mice 2 and 12 weeks after DDC treatment. The fold induction of cytokine mRNA levels is shown $\left({ }^{*} P<0.05 ;{ }^{* *} P<0.01\right)$. D: Displayed are photomicrographs of histochemical analysis of Sirius red-stained liver tissue sections derived from mice treated for 12 weeks with DDC. E: Hepatic collagen- $1 \alpha$ mRNA expression levels were determined by quantitative real-time PCR. RNA was isolated from mice before and 12 weeks after DDC treatment. The fold induction of cytokine mRNA levels is displayed $\left({ }^{*} P<0.05 ;{ }^{* *} P<0.01\right)$.

stellate cell activation, which was also associated with increased matrix cell production as evidenced by the enhanced collagen production.

As part of an adaptive and repair response to DDCinduced chronic toxic liver injury and block of hepatocyte proliferation the intrahepatic stem cell compartment is activated. ${ }^{3}$ Oval cells expand, depending on TNF- $\alpha$ and 
IL-6 expression, ${ }^{6}$ in the periportal areas where they can differentiate into biliary duct-forming structures and hepatocytes. In our model the progenitor cell induction rate directly correlated with the lack of STAT3 activation in hepatocytes and thus with the degree of hepatocellular injury. Interestingly, DDC treatment in IL-6 knockout mice resulted in a liver phenotype similar to that found in the wild-type group and injury was not enhanced (data not shown). Thus, the sole use of IL-6 $6^{21}$ knockout mice apparently does not completely reflect the complexity of the DDC model as gp130 can be redundantly activated by other cytokines as well.

Recent results in a different mode ${ }^{26}$ indicate that oval cell induction and proliferation is dependent on STAT ${ }^{8}$ in progenitor cells itself. Therefore, our results could suggest that besides IL-6 other family members can either substitute for the loss of IL-6 or are more relevant for either hepatocellular protection or oval cell induction in the DDC model. Oncostatin M, an interesting candidate, therefore fulfills a dual role. Although the cytokine was shown to inhibit oval cell growth in vitro, ${ }^{27}$ its overexpression attenuates liver injury. ${ }^{28}$ Interestingly it can also promote hepatic differentiation. ${ }^{29}$ However, only studies using oncostatin $\mathrm{M}$ knockout mice, which are not available yet, could further highlight the relevance of this cytokine for oval cell physiology in vivo.

The link between oval cell induction and fibrosis progression is still not fully understood. Recent data suggest that extracellular matrix components are involved in preparing the niche for the expansion of liver progenitor cells. ${ }^{27}$ Thus, stronger fibrosis progression in gp $130^{\Delta \text { hepa }}$ and gp $130^{\Delta \text { hepaSTAT }}$ mice might further enhance oval cell proliferation. However, this is not likely to be the only mechanism, as oval cells are uniformly induced in different models, ${ }^{30}$ regardless of the underlying mechanism. Therefore, a closer look at oval cell activation and other hepatic progenitor cells in different chronic liver injury models could further help to delineate these mechanisms.

In our study gp $130^{\Delta \text { hepa }}$ and gp $130^{\Delta h e p a S T A T}$ mice showed the strongest oval cell activation after DDC treatment, making it very likely that gp130-dependent signaling is functional in oval cells of these mice. Therefore, these results support the data of Yeoh et $\mathrm{al}^{8}$ that STAT signaling within oval cells must be intact for their activation during liver injury. However, because the isolation of pure oval cells is unreliable, we cannot completely exclude minor Cre activation in oval, cells especially once they start to differentiate into albumin-expressing cells and are morphologically no longer distinguishable from hepatocytes.

Our present data thus suggest that gp130/STAT3-dependent signaling in hepatocytes is an essential mechanism during chronic cholestatic liver injury. STAT signaling in hepatocytes provides antiapoptotic cytoprotection. Deletion of this pathways abolishes the induction of the acute-phase response, thus leading to more severe cholestasis and an enhanced inflammatory response with increased TNF- $\alpha$ expression and subsequent cytotoxicity. This greater injury, being evident already during the early phase of DDC treatment, triggers a stronger stellate cell activation and profibrogenic response, which overall leads to an enhanced oval cell response in the livers of these animals.

\section{References}

1. Fickert $P$, Stoger U, Fuchsbichler A, Moustafa T, Marschall HU, Weiglein AH, Tsybrovskyy O, Jaeschke H, Zatloukal K, Denk H, Trauner M: A new xenobiotic-induced mouse model of sclerosing cholangitis and biliary fibrosis. Am J Pathol 2007, 171:525-536

2. Beer S, Komatsubara K, Bellovin DI, Kurobe M, Sylvester K, Felsher DW: Hepatotoxin-induced changes in the adult murine liver promote MYC-induced tumorigenesis. PLoS ONE 2008, 3:e2493

3. Wang X, Foster M, Al-Dhalimy M, Lagasse E, Finegold M, Grompe M The origin and liver repopulating capacity of murine oval cells. Proc Natl Acad Sci USA 2003, 100(Suppl 1):11881-11888

4. Subrata LS, Lowes KN, Olynyk JK, Yeoh GC, Quail EA, Abraham LJ: Hepatic expression of the tumor necrosis factor family member lymphotoxin- $\beta$ is regulated by interleukin (IL)- 6 and IL-1 $\beta$ : transcriptional control mechanisms in oval cells and hepatoma cell lines. Liver Int 2005, 25:633-646

5. Nguyen LN, Furuya MH, Wolfraim LA, Nguyen AP, Holdren MS Campbell JS, Knight B, Yeoh GC, Fausto N, Parks WT: Transforming growth factor- $\beta$ differentially regulates oval cell and hepatocyte proliferation. Hepatology 2007, 45:31-41

6. Knight B, Yeoh GC, Husk KL, Ly T, Abraham LJ, Yu C, Rhim JA Fausto $\mathrm{N}$ : Impaired preneoplastic changes and liver tumor formation in tumor necrosis factor receptor type 1 knockout mice. J Exp Med 2000, 192:1809-1818

7. Ruddell RG, Knight B, Tirnitz-Parker JE, Akhurst B, Summerville L, Subramaniam VN, Olynyk JK, Ramm GA: Lymphotoxin- $\beta$ receptor signaling regulates hepatic stellate cell function and wound healing in a murine model of chronic liver injury. Hepatology 2009, 49:227-239

8. Yeoh GC, Ernst M, Rose-John S, Akhurst B, Payne C, Long S, Alexander W, Croker B, Grail D, Matthews VB: Opposing roles of gp130mediated STAT-3 and ERK-1/2 signaling in liver progenitor cell migration and proliferation. Hepatology 2007, 45:486-494

9. Streetz KL, Wustefeld T, Klein C, Kallen KJ, Tronche F, Betz UA Schutz G, Manns MP, Muller W, Trautwein C: Lack of gp130 expression in hepatocytes promotes liver injury. Gastroenterology 2003, 125:532-543

10. McLoughlin RM, Jenkins BJ, Grail D, Williams AS, Fielding CA, Parker CR, Ernst M, Topley N, Jones SA: IL-6 trans-signaling via STAT3 directs $T$ cell infiltration in acute inflammation. Proc Natl Acad Sci USA 2005, 102:9589-9594

11. Ernst M, Inglese M, Waring $P$, Campbell IK, Bao S, Clay FJ, Alexander WS, Wicks IP, Tarlinton DM, Novak U, Heath JK, Dunn AR: Defective gp130-mediated signal transducer and activator of transcription (STAT) signaling results in degenerative joint disease, gastrointestinal ulceration, and failure of uterine implantation. J Exp Med 2001, 194:189-203

12. Kellendonk C, Opherk C, Anlag K, Schutz G, Tronche F: Hepatocytespecific expression of Cre recombinase. Genesis 2000, 26:151-153

13. Betz UA, Bloch W, van den Broek M, Yoshida K, Taga T, Kishimoto T, Addicks K, Rajewsky K, Muller W: Postnatally induced inactivation of gp130 in mice results in neurological, cardiac, hematopoietic, immunological, hepatic, and pulmonary defects. J Exp Med 1998, 188:1955-1965

14. Dierssen U, Beraza N, Lutz HH, Liedtke C, Ernst M, Wasmuth HE, Trautwein C: Molecular dissection of gp130-dependent pathways in hepatocytes during liver regeneration. J Biol Chem 2008, 283:9886-9895

15. Kopf M, Baumann H, Freer G, Freudenberg M, Lamers M, Kishimoto $\mathrm{T}$, Zinkernagel R, Bluethmann $\mathrm{H}$, Kohler G: Impaired immune and acute-phase responses in interleukin-6-deficient mice. Nature 1994, 368:339-342

16. Strnad P, Stumptner C, Zatloukal K, Denk H: Intermediate filament cytoskeleton of the liver in health and disease. Histochem Cell Biol 2008, 129:735-749

17. Streetz KL, Tacke F, Leifeld L, Wustefeld T, Graw A, Klein C, Kamino K, Spengler U, Kreipe H, Kubicka S, Muller W, Manns MP, Trautwein 
C: Interleukin 6/gp130-dependent pathways are protective during chronic liver diseases. Hepatology 2003, 38:218-229

18. Klein C, Wustefeld T, Assmus U, Roskams T, Rose-John S, Muller M, Manns MP, Ernst M, Trautwein C: The IL-6-gp130-STAT3 pathway in hepatocytes triggers liver protection in T cell-mediated liver injury. J Clin Invest 2005, 115:860-869

19. Sander LE, Obermeier F, Dierssen U, Kroy DC, Singh AK, Seidler U, Streetz KL, Lutz HH, Muller W, Tacke F, Trautwein C: Gp130 signaling promotes development of acute experimental colitis by facilitating early neutrophil/macrophage recruitment and activation. J Immunol 2008, 181:3586-3594

20. Sun Z, Klein AS, Radaeva S, Hong F, El-Assal O, Pan HN, Jaruga B, Batkai S, Hoshino S, Tian Z, Kunos G, Diehl AM, Gao B: In vitro interleukin-6 treatment prevents mortality associated with fatty liver transplants in rats. Gastroenterology 2003, 125:202-215

21. Ezure T, Sakamoto T, Tsuji H, Lunz JG 3rd, Murase N, Fung JJ, Demetris AJ: The development and compensation of biliary cirrhosis in interleukin-6-deficient mice. Am J Pathol 2000, 156:1627-1639

22. Liu Z, Sakamoto T, Yokomuro S, Ezure T, Subbotin V, Murase N, Contrucci S, Demetris AJ: Acute obstructive cholangiopathy in interleukin-6 deficient mice: compensation by leukemia inhibitory factor (LIF) suggests importance of gp-130 signaling in the ductular reaction. Liver 2000, 20:114-124

23. Kovalovich K, Li W, DeAngelis R, Greenbaum LE, Ciliberto G, Taub R: Interleukin-6 protects against Fas-mediated death by establishing a critical level of anti-apoptotic hepatic proteins FLIP, Bcl-2, and Bcl-xL. J Biol Chem 2001, 276:26605-26613
24. Graf D, Kohlmann C, Haselow K, Gehrmann T, Bode JG, Haussinger D: Bile acids inhibit interleukin-6 signaling via gp130 receptor-dependent and -independent pathways in rat liver. Hepatology 2006, 44:1206-1217

25. Rust C, Wild N, Bernt C, Vennegeerts T, Wimmer R, Beuers U: Bile acid-induced apoptosis in hepatocytes is caspase-6-dependent. J Biol Chem 2009, 284:2908-2916

26. Kahraman A, Barreyro FJ, Bronk SF, Werneburg NW, Mott JL, Akazawa Y, Masuoka HC, Howe CL, Gores GJ: TRAIL mediates liver injury by the innate immune system in the bile duct-ligated mouse. Hepatology 2008, 47:1317-1330

27. Matthews VB, Knight B, Tirnitz-Parker JE, Boon J, Olynyk JK, Yeoh GC: Oncostatin M induces an acute phase response but does not modulate the growth or maturation-status of liver progenitor (oval) cells in culture. Exp Cell Res 2005, 306:252-263

28. Hamada T, Sato A, Hirano T, Yamamoto T, Son G, Onodera M, Torii I, Nishigami T, Tanaka M, Miyajima A, Nishiguchi S, Fujimoto J, Tsujimura $\mathrm{T}$ : Oncostatin M gene therapy attenuates liver damage induced by dimethylnitrosamine in rats. Am J Pathol 2007, 171:872-881

29. Okaya A, Kitanaka J, Kitanaka N, Satake M, Kim Y, Terada K, Sugiyama T, Takemura M, Fujimoto J, Terada N, Miyajima A, Tsujimura T: Oncostatin M inhibits proliferation of rat oval cells, OC15-5, inducing differentiation into hepatocytes. Am J Pathol 2005, 166:709-719

30. Jelnes P, Santoni-Rugiu E, Rasmussen M, Friis SL, Nielsen JH, Tygstrup N, Bisgaard HC: Remarkable heterogeneity displayed by oval cells in rat and mouse models of stem cell-mediated liver regeneration. Hepatology 2007, 45:1462-1470 